\title{
GEOGRAFIA DA RELIGIÃO NO BRASIL: censos demográficos e transformações recentes
}

\author{
Msc. Fernando Raphael Ferro de Lima \\ Doutorando em Geografia da UFPR \\ Rua Maximo João Kopp, 274, bloco 1. Santa Cândida, CEP:82630-900 - Curitiba, Paraná, Brasil \\ Telfax. : (41) 33516398 - fernandoraphaelferro@yahoo.com.br \\ Prof. Dr. Agemir de Carvalho Dias \\ agemir@terra.com.br
}

\begin{abstract}
RESUMO
A diversidade religiosa é um importante elemento caracterizador das sociedades modernas. Desde a constituição de 1891 o Brasil não possui mais uma religião oficial, de modo que a tolerância o trânsito religioso são permitidos e tidos, inclusive, como direito dos brasileiros. Neste texto é trabalhada a distribuição espacial dos fiéis no Brasil, tendo por base os dados do Censo Demográfico de 2000. As dinâmicas de colonização do território brasileiro afetaram de forma diferenciada a distribuição dos agrupamentos religiosos pelo país. A partir destes dados podemos fazer algumas observações gerais sobre a dinâmica espacial dos fiéis no país.
\end{abstract}

Palavras-chave: Ireligião; dinâmica populacional; migração.

\begin{abstract}
Religious diversity is an important element that characterizes modern societies. Since the constitution of 1891, Brazil no longer has an official religion, so the change of religions and the tolerance is allowed and taken, including, as a constitutional right. This text is worked out the spatial distribution of the faithful in Brazil, based on Census 2000 data. The dynamics of colonization of the Brazilian territory affected differently the distribution of religious groups around the country. From these data we can make some general observations about the spatial dynamics of the faithful in the country.
\end{abstract}

Key words: religion, populational dinamics, migration.

\section{RESUMEN}

La diversidad religiosa es un importante elemento caracterizador de las sociedades modernas. Desde la Constitución de 1891, Brasil ya no tiene una religión oficial, de modo que el tránsito de la tolerancia religiosa es permitida y reconocida como un derecho de los brasileños. Este texto trabaj sobre la distribución espacial de los fieles en Brasil, basado en datos del Censo 2000. La dinámica de la colonización del territorio brasileño afecta de manera diferente la distribución de los grupos religiosos en todo el país. De estos datos podemos hacer algunas observaciones generales acerca de la dinámica espacial de los fieles en el país.

Palabras-clave: religíon; dinamica poblacional; migracíon.

\section{Introdução}

A diversidade religiosa é um importante elemento caracterizador das sociedades modernas. Desde a constituição de 1891 o Brasil não possui mais uma religião oficial, de modo que a tolerância o trânsito religioso são permitidos e tidos, inclusive, como direito dos brasileiros (ORO, 2008). Isto não significa que ao longo de todo este período não tenha ocorrido conflitos entre as diversas religiões no país, tampouco que não tenham ocorrido episódios de perseguição a grupos minoritários. Mas de um modo geral, as pessoas são livres para buscar a religião que mais lhe agrade, e de praticá-la da forma que lhe convier, sob a proteção do estado brasileiro.

Depois da constituição de 1988 a proteção da pratica religiosa foi ampliada, de modo que a discriminação religiosa é encarada como crime tão grava quanto o racismo, o que contribui para a valorização e respeito às crenças minoritárias no país. As religiões historicamente excluídas e desvalorizadas passam a ter seu direito de existir reconhecidos, e com garantias legais contra a eventual perseguição religiosa. A tolerância, deste modo, pode ser ampliada no país. 
Este arcabouço legal de proteção às religiões minoritárias no país permitiu que na segunda metade do século XX o país conhecesse o início de um processo de alteração do perfil religioso da população. Ao longo deste capítulo iremos trabalhar a distribuição espacial dos fiéis no Brasil, tendo por base os dados do Censo Demográfico de 2000. Estes dados contêm diversas informações sobre as pessoas que compõem cada uma das religiões atuantes no país, e permite que tenhamos uma idéia mais clara sobre o perfil dos fiéis, sobretudo características socioeconômicas.

\section{Teses sobre a religião no Brasil}

O primeiro aspecto a se considerar sobre a religião no Brasil é que esta é umas das variáveis sociodemográficas que mais mudaram no país, ao lado da incorporação do gênero feminino ao mercado de trabalho e crescente escolarização da população. Este processo se deu a partir de uma redução da participação do catolicismo romano por outras formas de expressão religiosa (NERI, 2008). Uma das hipóteses é que grande parte desta mudança se deu entre as camadas mais pobres dos grandes centros urbanos (ALMEIDA, 2004).

A liberdade religiosa, que também pode ser entendida como liberdade de consciência, é considerada a "mãe" de todas as outras liberdades; sob ela se assenta o direito à privacidade, um dos pilares do liberalismo moderno. No Brasil, a liberdade religiosa foi consolidada pela constituição de 1891, com a separação entre Estado e Igreja. Obviamente que o principal alvo desta separação foi reduzir o poder da Igreja Católica Apostólica Romana sobre atos civis, como o matrimônio, por exemplo.

No entanto, com o decorrer do século XX, foram diversos os esforços de reconhecimento das outras religiões, conduzindo a processo de institucionalização, sobretudo dos espíritas e dos umbandistas, cujas práticas eram perseguidas como "magia" e ilegal da medicina pelos órgãos repressores do Estado.

A liberdade de escolha da religião, os processo de urbanização, a dinâmica atuação proselitista das igrejas evangélicas e o uso intensivo dos meios de comunicação por parte dos agrupamentos religiosos fizeram com que o trânsito religioso, isto é, a troca de uma religião por outra se tornasse um fenômeno relativamente comum no país, sobretudo nas últimas décadas. Estima-se que pelos menos 1/4, ou seja, 25\% dos brasileiros com mais de 16 anos já tenham mudado de religião (ALMEIDA, 2004, p.17), o que caracteriza uma situação de competição e desequilíbrio na demografia religiosa brasileira.

Outro fator importante é o crescimento das pessoas que se declaram sem religião, o que leva a formulação de diversas questões. Um delas é se isso poderia significar um avanço da secularização no país. Outra questão que se coloca, é se isso está relacionado às pessoas que se encontram em trânsito religioso, ou seja, não se sentem pertencentes à religião de origem, tampouco à religião de destino. Seria importante também poder dimensionar quanto cada uma destas hipóteses é verdadeira, já que o mais provável é que o avanço dos sem religião signifique tanto uma coisa quanto a outra.

O trânsito religioso no Brasil ocorre principalmente a partir da religião católica em direção às outras religiões, e das diversas religiões em direção aos evangélicos pentecostais, que por sua vez geram também retorno às religiões de origem. Almeida (2004) observou diversos fatores relacionados à mudança religiosa, dentro os quais se destaca o papel da migração como fator de influência. Ele observa em seu estudo que os nordestinos, que no nordeste são majoritariamente católicos, quando migram para o Sudeste tendem a se tornar evangélicos devido ao contato com as diversas igrejas evangélicas pentecostais que formaram uma grande rede nas periferias das grandes cidades brasileiras (ALMEIDA, 2004, p. 21).

Outra questão que se coloca no país é a do sincretismo religioso. O sincretismo caracteriza-se pela mistura entre duas ou mais religiões ou, ainda, sua prática simultânea. Para fins estatísticos, o sincretismo religioso coloca-se como um problema de difícil solução, pois os questionários censitários costumam realizar a pergunta tendo em vista a opção por uma das respostas. Do mesmo modo, quando o entrevistado responde, ele pode ter em mente apenas a religião à qual julga pertencer por algum critério subjetivo, como laço familiar, status sócio-econômico, ou ainda preconceito religioso. Deste modo, nos dados oficiais algumas religiões/grupos religiosos aparecem sub-representados, como as religiões afro-brasileiras, sobretudo a umbanda e o candomblé. 


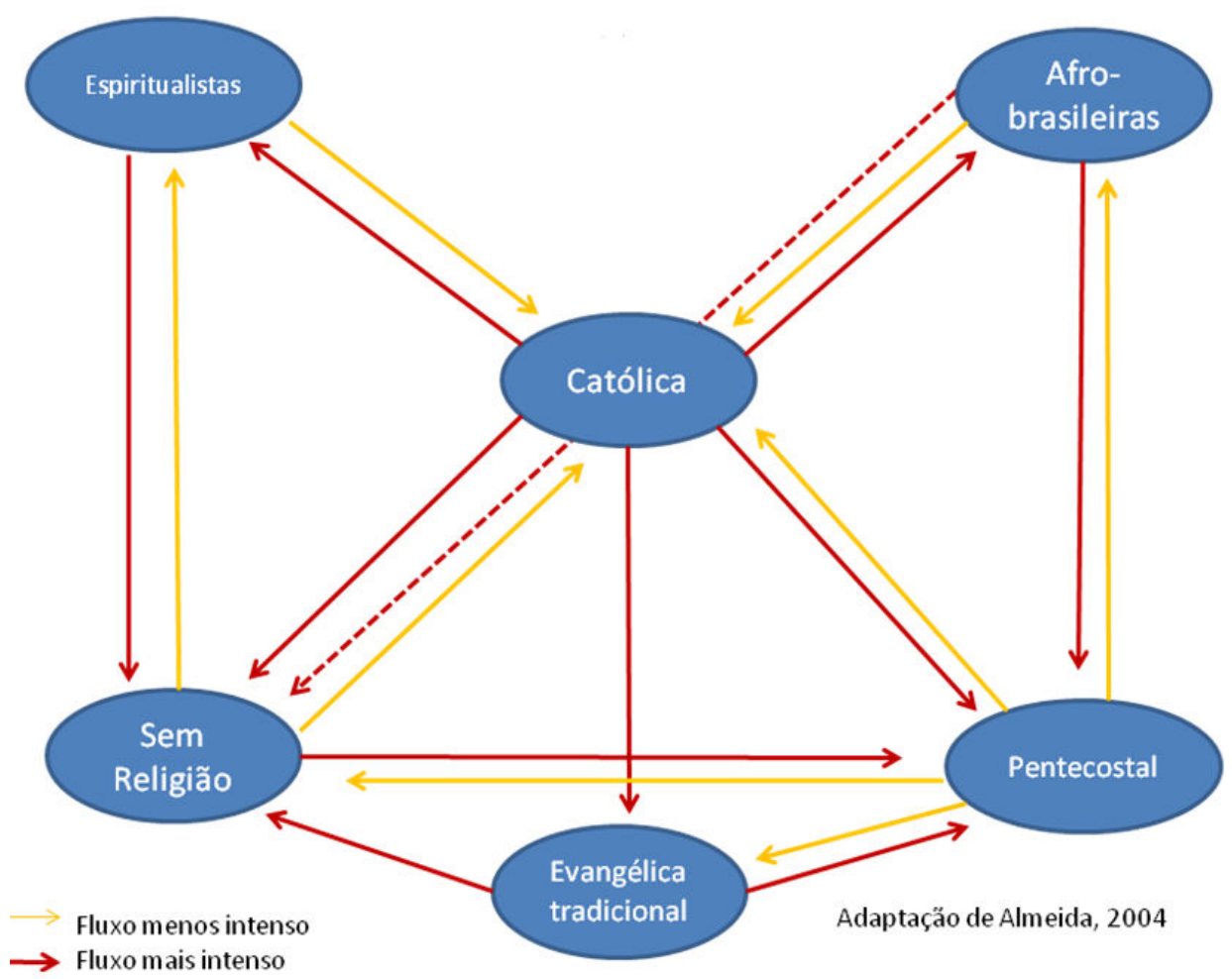

Figura 1 - Principais fluxos do trânsito religioso no Brasil

A hipótese explicativa é que os mais pobres tendem a declarar-se como católicos, do mesmo modo que os negros, ocultando ao recenseador sua prática religiosa de fato. Neste ponto de vista, alguns autores apontam as religiões evangélicas, sobretudo as tradicionais, como aquelas dotadas de identidade mais definida. Os católicos costumam agrupar-se em duas situações: praticantes e não-praticantes, divisão esta associada a freqüência regular ao culto religioso, sendo que este último grupo, com baixa ou nenhuma freqüência ao culto.

Na seqüência iremos apresentar os dados populacionais do censo demográfico de 2000, procurando comparar os resultados observados com as teses acima levantadas.

\section{Religiões no censo brasileiro}

Como já foi colocado, a instituição da liberdade religiosa no Brasil se deu a partir da proclamação da república, quando ocorreu a separação formal entre igreja e estado. Todavia, esta separação foi marcada pela afirmação do Estado nacional frente à Igreja Católica. Com isso, as disputas destes processos ocorreram no sentido de barrar o avanço do positivismo sobre as instituições republicanas, com vistas a garantir que o país, apesar de laico, continuasse cristão.

Antes deste marco, porém, já havia no Brasil a presença de numerosas outras religiões. O judaísmo instalara-se no país quando da ocupação dos Holandeses ainda no século XVII; os imigrantes europeus vindos na segunda metade do século XIX trouxeram diversas ramificações do cristianismo reformado para o país, e, também, do cristianismo ortodoxo oriental. A migração de japoneses foi acompanhada da introdução de religiões orientais, como o budismo e o xintoísmo.

Além destes fatores, relacionados diretamente à entrada de pessoas das variadas partes do mundo do Brasil, é necessário reconhecer também a presença de práticas religiosas indígenas e africanas, ou afro-brasileiras, que eram perseguidas pela polícia, tornadas clandestinas, mas ainda assim, parte do 
cotidiano de grande parte da população brasileira. Deste modo, a produção de informações sobre o assunto percorreu uma longa estrada, e está, ainda, marcada por inúmeras imperfeições na coleta de dados, das quais algumas foram comentadas.

Desde 1940 os censos incluem perguntas sobre a religião praticada pelo entrevistado. Em todo período, com exceção de 1970, esta foi uma pergunta aberta. Em 1970 o IBGE adotou seis categorias como referência. Elas foram ampliadas para nove em 1980, 43 em 1991 e 143 em 2000. O aumento das categorias de enquadramento das respostas é testemunho do crescimento da diversidade religiosa no Brasil (Figura 2).

Para fins de comparação, tendo em vista as limitações dos censos anteriores a 2000, a comparação ao longo do período pode ser feita entre estes grupos populacionais. Pelo gráfico observa-se que a proporção de católicos caiu gradativamente no país, com uma aceleração nesta queda a partir dos anos 1970. Ao longo deste mesmo período ocorreu um crescimento dos grupos evangélicos, sobretudo a partir de 1991, e dos sem religião, que vem aumentando de forma constante desde 1980. Os outros grupos religiosos têm mantido uma participação relativamente constante na população brasileira, em torno de $3 \%$ do total nacional.

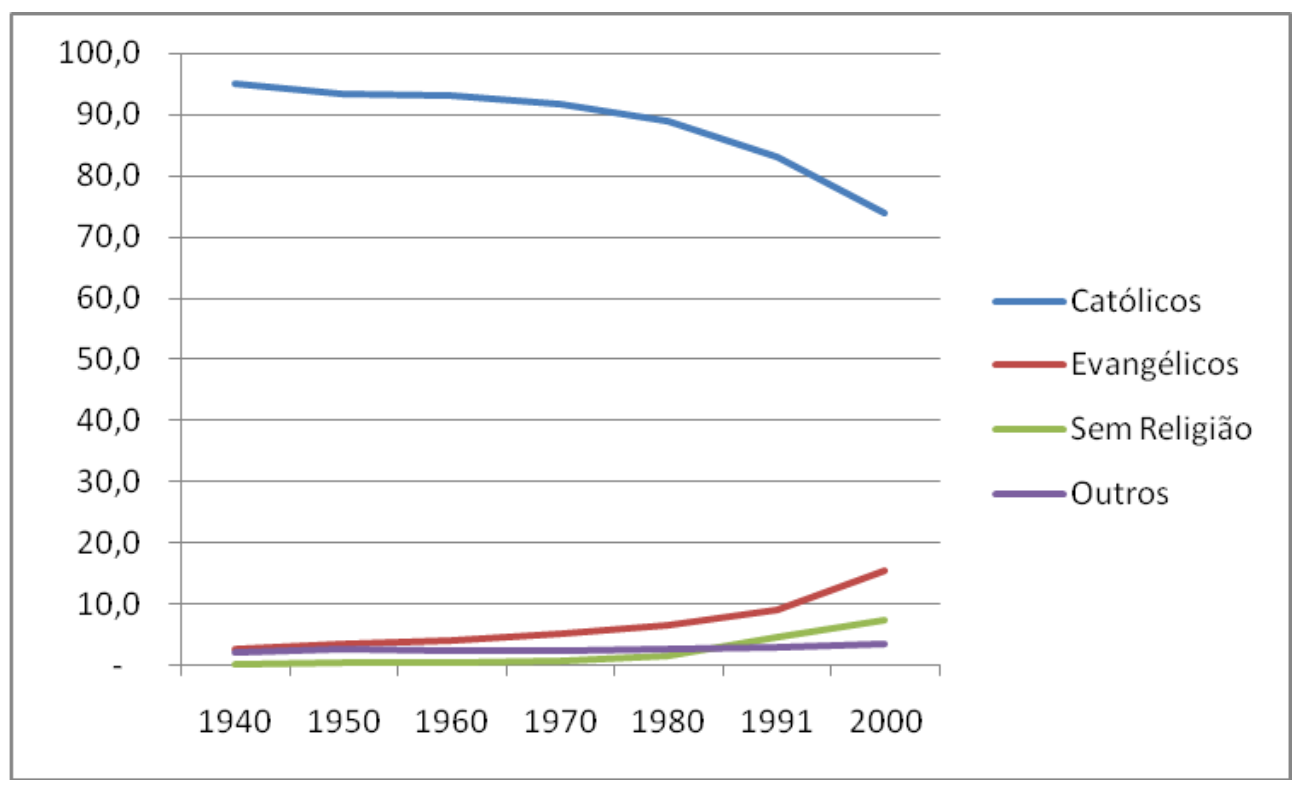

Fonte: IBGE

Figura 2 - Dinâmica das religiões no Brasil - 1940 -2000.

O crescimento explosivo dos evangélicos nos anos 1990, entretanto, está ligado à consolidação dos evangélicos pentecostais. Em 1970 5,8\% da população brasileira era composta por evangélicos. Neste censo ainda não havia a possibilidade de diferenciar os pentecostais dos protestantes históricos ou tradicionais. Em 1980 o percentual de protestantes chegara a 6,6\% da população, sendo que 3,4\% eram de protestantes históricos e 3,2\% de pentecostais.

Em 1991 os pentecostais haviam chegado a 6\% da população e os protestantes históricos caíram para 3\%. Nota-se, portanto, que parte do crescimento dos evangélicos neste período se deu pela mudança de religião de católicos e parte pela migração de protestantes históricos. Nos anos 1990, porém, ocorre um aumento generalizado dos evangélicos, com um aumento tanto dos protestantes históricos, que passam de $3 \%$ para $5 \%$, quanto dos pentecostais, que passam de 6\% para 10,6\% em 2000.

A tabela 1 lista os 10 maiores agrupamentos religiosos do país, considerando inclusive aqueles que se declaram sem religião. Deve-se destacar que a tabela foi elaborada tendo por base as informações do 
censo de 2000 do IBGE, e, portanto, a denominação das igrejas,/ grupos religiosos não coincide com a forma como o grupo se autodenomina ${ }^{1}$.

Tabela 1 - Dez maiores Igrejas/Grupos Religiosos - número de fiés e dados relativos

\begin{tabular}{llrr}
\hline \multicolumn{1}{c}{ IG REJA/GRUPO RE LIGI OSO } & FIÉ IS & $(\%)$ \\
\hline 1 & Catól ica Apostólica Romana & TOTAL & 73,5 \\
2 & Sem Reli gião & 124.941 .084 & 7,4 \\
3 & Igreja Evangélica Assembléia de Deus & 12.492 .403 & 4,9 \\
4 & Igreja Evangélica Batista & 8.303 .869 & 1,7 \\
5 & Igreja Congregacional Cristã do Brasil & 2.932 .706 & 1,5 \\
6 & Espírita, Kardecista & 2.483 .918 & 1,3 \\
7 & Igreja Universal do Reino de Deus & 2.242 .886 & 1,2 \\
8 & Outras Igrej as Evangélicas Pentecostais & 2.101 .826 & 0,9 \\
9 & Igreja Evangelho Quadrangular & 1.507 .967 & 0,8 \\
10 & Igreja Evangélica Adventista do Sétimo Dia & 1.307 .027 & 0,7 \\
\hline
\end{tabular}

É possível perceber que a igreja com maior número de adeptos no país continua sendo a Igreja Católica Apostólica Romana (ICAR), mas o segundo maior grupo é composto por pessoas que se declaram sem religião. AAssembléia de Deus, $\left(3^{\mathrm{a}}\right)$ a Congregação Cristã (5), Universal do Reino de Deus (IURD, $7^{\mathrm{a}}$ ) e a Igreja do Evangelho Quadrangular ( $\left.9^{\mathrm{a}}\right)$ são todas igrejas consideradas pentecostais. A Igreja Adventista enquadra-se na categoria Outras Igrejas Evangélicas no censo de 2000, sendo que a única igreja protestante tradicional ou de missão listada entre as dez maiores confissões do país é a Convenção Batista Brasileira (CBB). Estas informações dão a mostra da fragmentação mais acentuada das igrejas evangélicas de missão.

Através da observação das informações sócio-econômicas podemos compreender melhor o perfil dos fiéis de cada um destes grupos. Para tanto, iremos classificar os grupos de acordo com a sistemática adotada pelo censo demográfico de 2000.

A tabela 2 mostra que os católicos, por formarem o maior contingente da população formam, de certo modo, a média do país. Observa-se que os evangélicos e os sem religião, juntamente com o agrupamento outras religiões são os grupos que possuem a renda per capita mais baixa. De todos estes grupos, porém, são os pentecostais os mais pobres. Na outra ponta destacam-se os praticantes das religiões espiritualistas, das religiões orientais e das religiões afro-brasileiras como pertencentes aos grupos de renda mais elevada. No caso das religiões orientais e espiritualistas a diferença nos rendimentos é significativamente superior a média nacional. 
Tabela 2 - Características sócioeconômicas dos agrupamentos religiosos

\begin{tabular}{|c|c|c|c|c|}
\hline AGRUPAMENTO REL IGIOSO & $\begin{array}{l}\text { NÚMERO DE } \\
\text { PESSOAS }\end{array}$ & $\begin{array}{l}\text { PART ICIPAÇÃO } \\
\text { NO TOTAL } \\
\text { NACIONAL (\%) }\end{array}$ & $\begin{array}{c}\text { RENDA } \\
\text { MÉDIA PE R } \\
\text { CAPIT A (R\$) }\end{array}$ & $\begin{array}{c}\text { RENDA EM } \\
\text { RELAÇÃO À } \\
\text { MÉDIA NACIONAL } \\
=100 \\
\end{array}$ \\
\hline Católica & 125527349 & 73,9 & 298,8 & 100,5 \\
\hline Evangélica & 26184941 & 15,4 & 247,7 & 83,3 \\
\hline Evangélicos de Missão & 6943510 & 4,1 & 358,8 & 120,7 \\
\hline Evangélicos Pentecostais & 18684787 & 11,0 & 229,0 & 77,0 \\
\hline Outros Evangélicos & 556646 & 0,3 & 2502 & 84,2 \\
\hline Sem religião & 12492403 & 7,4 & 270,6 & 91,0 \\
\hline Espiritual ista & 2288290 & 1,3 & 786,1 & 264,4 \\
\hline Afro-brasileira & 525012 & 0,3 & 389,9 & 131,2 \\
\hline Orien tais & 490753 & 0,3 & 962,2 & 323,7 \\
\hline Outras Religiões & 2364107 & 1,4 & 272,8 & 91,8 \\
\hline TOTAL & 169872855 & 100 & 297,3 & 100 \\
\hline
\end{tabular}

Fonte: FGV/IBGE

A tabela 3 mostra que o predomínio dos católicos na população é maior na zona rural que na nas cidades, razão inversa do que ocorrem em todos os outros agrupamentos religiosos. Os espiritualistas são um grupo populacional majoritariamente urbano, com 96,8\% de seus adeptos vivendo nesta situação de domicílio. O mesmo ocorre, de um modo geral, com todos os agrupamentos, excetuando-se os evangélicos e os católicos e os sem religião.

Decompondo esta tabela, percebe-se também que os agrupamentos religiosos não católicos adquirem uma importância maior nas grandes cidades, sobretudo nas regiões metropolitanas. A tabela 4 mostra que quase $75 \%$ dos fiéis das religiões afro-brasileiras e orientais encontram-se em municípios que compõem regiões metropolitanas, o que é verdade para cerca de 60\% dos espíritas. Enquanto isso, apenas 35,6\% dos católicos vive neste tipo de município. Os evangélicos possuem uma presença muito mais expressiva nos municípios grandes e metropolitanos que nos municípios pequenos, sendo que os católicos que moram nas zonas rurais só não são mais números que aqueles vivendo em regiões metropolitanas.

Tabela 3 - Grupos religiosos por situação de domicílio - 2000

\begin{tabular}{l|r|rrr}
\multicolumn{1}{c|}{$\begin{array}{c}\text { AGRUPAMENT OS } \\
\text { RELIGIOSOS }\end{array}$} & \multicolumn{3}{c}{ URB ANO } & \multicolumn{2}{c}{ RURAL } \\
Católicos & TOTAL & $(\%)$ & TOTAL & $(\%)$ \\
Evangélicos & 97308179 & 77,5 & 28219170 & 22,5 \\
$\quad$ Evangélico de Missão & 22313922 & 85,2 & 3871018 & 14,8 \\
$\quad$ Evangélico Pentecostal & 5921639 & 85,3 & 1021871 & 14,7 \\
$\quad$ Outros Evangélicos & 15897480 & 85,1 & 2787305 & 14,9 \\
Sem Rel igião & 494802 & 88,9 & 61843 & 11,1 \\
Espiritual ista & 10709456 & 85,7 & 1782947 & 14,3 \\
Afro-brasileira & 2215514 & 96,8 & 72775 & 3,2 \\
Orien tais & 502746 & 95,8 & 22268 & 4,2 \\
Outras Religiões & 469487 & 95,7 & 21268 & 4,3 \\
Total & 2096641 & 88,7 & 267466 & 11,3 \\
& 135615945 & 79,8 & 34256912 & 20,2
\end{tabular}


A partir destes dados podemos fazer algumas observações gerais sobre a dinâmica espacial dos fiéis no país. Primeiramente, que os agrupamentos evangélicos, sobretudo os pentecostais, são parte de um fenômeno urbano, muito destacado nas grandes cidades. As pessoas sem religião também são mais numerosas nos municípios metropolitanos e de grande porte. Isto reforça algumas das teses colocadas no começo do capítulo sobre o trânsito religioso. As pessoas, principalmente nas grandes cidades, costumam passar de sua religião de criação a uma situação sem religião. Depois, partem deste grupo em direção aos evangélicos pentecostais.

Tabela 4 - Distribuição por tipo de município (\%)

\begin{tabular}{|c|c|c|c|c|c|}
\hline GRUPO RELGIOSO & $\begin{array}{c}\text { REGIÃO } \\
\text { METROPOLITANA }\end{array}$ & $\begin{array}{l}\text { URBANO } \\
\text { GRANDE }\end{array}$ & $\begin{array}{l}\text { URBANO } \\
\text { MÉDIO }\end{array}$ & $\begin{array}{l}\text { URBANO } \\
\text { PEQUENO }\end{array}$ & RURAL \\
\hline Católicos & 35,6 & 14,6 & 18,8 & 11,3 & 19,7 \\
\hline Evangélicos & 47,3 & 16,4 & 16,6 & 8,3 & 11,4 \\
\hline Evangélico de Missão & 45,6 & 17,1 & 17,2 & 8,2 & 11,9 \\
\hline Evangélico Pentecostal & 47,8 & 16,0 & 16,4 & 8,5 & 11,3 \\
\hline Outros Evangélicos & 50,7 & 21,1 & 15,0 & 5,4 & 7,7 \\
\hline Sem Religião & 53,9 & 14,1 & 14,1 & 6,9 & 11,1 \\
\hline Afro-Brasileira & 73,2 & 14,7 & 8,1 & 2,1 & 1,9 \\
\hline Espiritual ista & 58,6 & 22,3 & 13,0 & 4,2 & 1,9 \\
\hline Orien tais & 72,6 & 14,4 & 8,4 & 2,4 & 2,2 \\
\hline Outras Religiões & 51,1 & 18,0 & 16,5 & 6,2 & 8,2 \\
\hline TOTAL & 39,5 & 15,0 & 17,9 & 10,3 & 17,3 \\
\hline
\end{tabular}

Fonte: CENSO/FVG

A primeira vista, há uma relação entre a expansão dos evangélicos pentecostais e o fenômeno da migração, tanto aquela campo/cidade, que marcou a urbanização no Brasil entre os anos 1950-1980, quanto à migração cidade pequena/cidade grande, que é o processo que tem se configurado mais recentemente. Também é possível observar que a redução relativa da população de católicos é maior nos grandes centros urbanos que nas cidades pequenas e zonas rurais.

Os dados do censo também permitem constatar que a diversidade religiosa é maior nas áreas urbanas, com destaque para as regiões metropolitanas. Como já foi observado nas zonas rurais o catolicismo ainda é muito forte, com uma presença muito tímida de outras tradições religiosas como o judaísmo, o islamismo e o budismo.

Alguns fenômenos merecem uma atenção mais detalhada. A relação entre ética protestante e prosperidade econômica não se confirma no Brasil, já que, de um modo geral, o protestantismo é um fenômeno mais ligado as populações de menor renda, sobretudo os protestantes pentecostais. Aparentemente, o apelo das chamadas "teologias da prosperidade" se daria entre estas parcelas mais carentes da população.

Outro dado que contraria o senso comum é o da renda per capita dos fiéis das religiões afrobrasileiras, que é superior a média nacional. Deste modo, parece ser um indício da hipótese levantada no começo do capítulo de que os mais pobres tendem a ocultar sua religiosidade, declarando-se apenas católico. Assim, cabe uma investigação mais detalhada sobre a extensão do sincretismo religioso no Brasil, que é tomado como maior do que os dados do senso permitem ver.

\section{Religiões por região}

Dado o tamanho do território e da população do Brasil, passamos agora para uma análise regional. Procuraremos compreender um pouco melhoras diferenças existentes entre as várias regiões do país. 
Para tanto, vamos avaliar os dados demográficos e de renda per capita para as macrorregiões definidas pelo IBGE. Começando pela Região Sul, notamos que depois da região Nordeste, é ela a que concentra maior proporção de católicos no país. No sul o padrão de que o pentecostalismo é um fenômeno ligado a pobreza urbana confirma-se, com os pentecostais aparecendo com a menor renda per capita da região. O padrão dos praticantes das religiões afro-brasileiras, porém, difere do nacional mostrando que no Sul os praticantes destas religiões encontram-se entre os estratos mais pobres da sociedade.

Tabela 5 - Participação no total e renda por grupo religioso, 2000 - região sul

\begin{tabular}{|c|c|c|c|c|}
\hline \multirow{2}{*}{ REGIÃO SUL } & \multicolumn{2}{|l|}{ FIÉIS } & \multicolumn{2}{|c|}{ RENDA } \\
\hline & TOTAL & $(\%)$ & VALOR (R\$) & ÍNDICE \\
\hline Católicos & 19506758 & 77,7 & 347,10 & 101 \\
\hline Evangélicos & 3849564 & 15,3 & 286,35 & 84 \\
\hline Evangélicos de Missão & 1424810 & 5,7 & 406,20 & 119 \\
\hline Evangélico Pentecostal & 2344883 & 9,3 & 215,20 & 63 \\
\hline Outros Evangélicos & 79871 & 0,3 & 237,39 & 69 \\
\hline Sem Rel igião & 988603 & 3,9 & 347,67 & 102 \\
\hline Afro-Brasileiro & 132729 & 0,5 & 259,61 & 76 \\
\hline Espiritual ista & 294581 & 1,2 & 715,29 & 209 \\
\hline Orien tais & 53043 & 0,2 & 927,84 & 271 \\
\hline Outras Religiões & 285070 & 1,1 & 299,68 & 88 \\
\hline Total & 25110348 & 100 & 342,36 & 100 \\
\hline
\end{tabular}

OBS: O Índice refere-se a qual a relação da renda daquele grupo em relação a variável total, ao fim da tabela. Assim, um índice 101, significa que a renda média é $1 \%$ maior que a renda média do total da população.

Fonte: IBGE

A disparidade de renda dos praticantes das religiões orientais e espiritualistas permanece, mas é inferior àquela encontrada em nível nacional. Os sem religião aparecem com uma renda per capita bem próxima a média, e são menos numerosos que no restante do país, representando menos de $4 \%$ da população total.

Na região sudeste a proporção de católicos é inferior a média nacional, influenciado, sobretudo, pela presença bastante acentuada de evangélicos e sem religião nos estados do Rio de Janeiro e Espírito Santo, com diferenças substanciais entre ambos. Os sem religião chegam a 8,4\% do total, valor bem mais elevado que na região sul, apesar de próximo a média nacional.

Os outros padrões repetem a dinâmica nacional. Deve-se destacar, porém, que a maior parte dos praticantes de outras religiões, dos espiritualistas e dos fiéis de religiões orientais encontra-se nesta região do país. 
Tabela 6 - Participação no total e renda por grupo religioso, 2000 região sudeste

\begin{tabular}{l|rrrr}
\multicolumn{1}{r}{ REGIÃO SUDESTE } & \multicolumn{2}{c}{ FIÉ IS } & \multicolumn{2}{c}{ RENDA } \\
& TOTAL & \multicolumn{1}{c}{ VALOR (RS) } & ÍNDICE \\
\hline Católicos & 50284454 & 69,42 & 405,19 & 104 \\
Evangélicos & 12685289 & 17,51 & 281,01 & 72 \\
$\quad$ Evangélicos de Missão & 3101388 & 4,28 & 396,66 & 102 \\
Evangélico Pentecostal & 9302898 & 12,84 & 242,16 & 62 \\
$\quad$ Outros Evangélicos & 281003 & 0,39 & 290,77 & 75 \\
Sem Religião & 6084122 & 8,40 & 344,57 & 89 \\
Afro-Brasileiro & 320020 & 0,44 & 468,19 & 120 \\
Espiritual ista & 1446671 & 2,00 & 828,93 & 213 \\
Orien tai s & 367166 & 0,51 & $1.019,31$ & 262 \\
Outras Religiões & 1242471 & 1,72 & 321,71 & 83 \\
TOTAL & 72430193 & 100,00 & 388,77 & 100 \\
\hline
\end{tabular}

Fonte: IBGE

No Centro-Oeste os evangélicos atingem $18,9 \%$ da população, sendo em grande maioria de pentecostais. O percentual de pessoas sem religião também é elevado. Reduzida é a presença de pessoas praticantes de religiões orientais e de religiões afro-brasileiras. O comportamento da renda segue o padrão nacional, apesar do fato de os evangélicos de missão possuir uma renda mais alta que a média nacional deste mesmo agrupamento.

Tabela 7- Participação no total e renda por grupo religioso, 2000 região centro-oeste

\begin{tabular}{lrrrr}
\multicolumn{1}{c}{ REGIÃO CENTRO-OESTE } & \multicolumn{2}{c}{ FIÉIS } & \multicolumn{2}{c}{ RENDA } \\
& TOTAL & (\%) & VALOR (R) & ÍNDICE \\
\hline Católicos & 8081674 & 69,44 & 347,75 & 101 \\
Evangélicos & 2195666 & 18,87 & 288,03 & 84 \\
Evangélicos de Missão & 485803 & 4,17 & 473,65 & 138 \\
Evangélico Pentecostal & 1642169 & 14,11 & 234,03 & 68 \\
Outros Evangélicos & 67694 & 0,58 & 266,06 & 77 \\
Sem Rel igião & 912641 & 7,84 & 321,78 & 94 \\
Afro-Brasileiro & 16107 & 0,14 & 473,51 & 138 \\
Espiritual ista & 227743 & 1,96 & 797,47 & 232 \\
Orien tais & 25263 & 0,22 & 856,61 & 249 \\
Outras Religiões & 179563 & 1,54 & 284,82 & 83 \\
Total & 11638657 & 100 & 343,55 & 100 \\
\hline
\end{tabular}

Fonte: IBGE 
O perfil da região norte é semelhante ao do Centro-Oeste, diferenciando-se pelo maior percentual de católicos, mas também o maior percentual de evangélicos. Os pentecostais são a maioria novamente. O percentual de pessoas sem religião fica abaixo da média nacional, mas neste aspecto guarda grandes disparidades internas, com um elevado percentual deste grupo no estado de Rondônia, por exemplo.

As religiões afro-brasileiras e orientais têm pequena participação na região. Na categoria outras religiões, o percentual é elevado, o que dá mostra da presença da população indígena nesta região do país. Em relação à renda, o padrão é semelhante ao da região Centro-Oeste.

O Nordeste é a região do país onde a predominância dos católicos é mais ampla, e a participação dos evangélicos é menor. No caso do nordeste, cabe a observação de que a presença de católicos é muito mais forte no interior que no litoral, o que se justifica pelo fato de grande parte das grandes cidades nordestinas situarem-se no litoral. Nestas cidades, a participação de católicos se aproxima mais dos índices da região sudeste. Esta mesma diferenciação pode ser observada em relação a outras variáveis, como é possível observar em Almeida (2007)

Tabela 8 - Participação no total e renda por grupo religioso, 2000

\begin{tabular}{lrrrr} 
& \multicolumn{1}{c}{ FIÉ IS } & \multicolumn{2}{c}{ RENDA } \\
\multicolumn{1}{c}{ REGIÃO NORTE } & TOTAL & $(\%)$ & RENDA(R\$) & ÍNDICE \\
\hline Católicos & 9285464 & 71,92 & 183,84 & 101 \\
Evangélicos & 2550484 & 19,75 & 163,18 & 90 \\
$\quad$ Evangélicos de Missão & 557470 & 4,32 & 230,38 & 127 \\
$\quad$ Evangélico Pentecostal & 1928437 & 14,94 & 144,07 & 79 \\
$\quad$ Outros Evangélicos & 64580 & 0,50 & 153,78 & 85 \\
Sem Religião & 849152 & 6,58 & 172,36 & 95 \\
Afro-Brasileiro & 5518 & 0,04 & 277,33 & 153 \\
Espiritual ista & 50100 & 0,39 & 700,49 & 386 \\
Orien tais & 14537 & 0,11 & 652,82 & 360 \\
Outras Religiões & 155917 & 1,21 & 173,80 & 96 \\
TOTAL & 12911172 & 100,00 & 181,45 & 100 \\
\hline
\end{tabular}

Fonte: IBGE

É a única região em que a renda média dos evangélicos é superior a dos católicos. Também é a única região em que o grupo outras religiões apresenta renda acima da média. Contudo, deve-se destacar que a renda média de todo o Nordeste é, em geral, bastante inferior a renda média das outras regiões.

\section{Grupos religiosos no espaço nacional}

A avaliação dos dados do censo mostra diferenças significativas entre as várias regiões do Brasil. Avaliaremos estas diferenças a partir da divisão por grupos religiosos. Começaremos pelo grupo mais representativo em termos percentuais, avançando pelas grandes categorias utilizadas pelo censo.

Os católicos têm uma maior participação no total da população nas regiões Nordeste e Sul, ultrapassando $80 \%$ da população no Nordeste, contra uma média nacional de $74 \%$. No Piauí $90 \%$ da população é católica, maior percentual relativo do país, no extremo oposto do Rio de Janeiro, onde este agrupamento é menor, $56,2 \%$. O censo permite relacionar o recuo dos católicos com o crescimento dos 
evangélicos e dos sem religião.

Rio de Janeiro e Rondônia são os estados com menor população de católicos, e reforçando este argumento, é interessante notar que ambos são estados com grande percentual de migrantes em sua população. A presença de católicos é mais forte nos estados do Nordeste, mas em Santa Catarina este grupo ultrapassa $80 \%$ da população, o único estado em que isto ocorre fora da região nordeste. Em relação a este aspecto, estas regiões, principalmente o interior das regiões Sul e Nordeste, são áreas de esvaziamento populacional, ou seja, que cedem população, que vão em direção às capitais e aos estados das regiões Centro-Oeste e Norte.

Tabela 9 - Participação no total e renda por grupo religioso, 2000

\begin{tabular}{lrrrr}
\multicolumn{1}{r}{ REGIÃO NORDESTE } & \multicolumn{2}{c}{ FIÉIS } & \multicolumn{2}{c}{ RENDA } \\
& TOTAL & \multicolumn{1}{c}{ (\%) } & VALOR (R\$) & ÍNDICE \\
\hline Católicos & 38368998 & 80,30 & 152,44 & 98 \\
Evangélicos & 4903939 & 10,26 & 157,31 & 101 \\
$\quad$ Evangélicos de Missão & 1374041 & 2,88 & 235,43 & 152 \\
Evangélico Pentecostal & 3466400 & 7,25 & 126,15 & 81 \\
$\quad$ Outros Evangélicos & 63500 & 0,13 & 167,98 & 108 \\
Sem Rel igião & 3657888 & 7,66 & 136,72 & 88 \\
Afro-Brasileiro & 50642 & 0,11 & 222,31 & 143 \\
Espiritual ista & 269193 & 0,56 & 640,07 & 413 \\
Orien tais & 30744 & 0,06 & 572,06 & 369 \\
Outras Religiões & 501086 & 1,05 & 177,20 & 114 \\
TOTAL & 47782490 & 100,00 & 155,09 & 100 \\
\hline
\end{tabular}

Portanto, é possível concluir que o catolicismo decai nas regiões receptoras de imigrantes e nos grandes centros urbanos, mantendo-se forte nas regiões que cedem população. Uma explicação pode ser a dificuldade da igreja católica de atender adequadamente a população, já que o número de católicos por paróquia é superior a média nacional nas regiões receptoras de população e inferior a média nacional nas áreas de decrescimento populacional (ANTONIAZZI, 2008).

Como é possível observar no mapa 2, os evangélicos são quase $20 \%$ da população da região norte, mas apenas 10,3\% da população do Nordeste, seguindo uma lógica inversa a dos católicos: onde os evangélicos são mais fortes, os católicos são menos expressivos. Neste quesito, Rondônia se destaca como o estado mais evangélico do Brasil, com 27,2\% pertencendo a este agrupamento. Este número também é elevado no Espírito Santo e no Rio de Janeiro, com 25\% e 22\% respectivamente.

É interessante notar as diferenças internas no grupo de igrejas evangélicas. No Brasil costuma-se dividir os evangélicos em dois grandes grupos: o das igrejas do protestantismo histórico, que o IBGE classifica como evangélicas de missão, e o das igrejas evangélicas pentecostais. Como pudemos observar nas tabelas anteriores, os evangélicos de missão são minoria entre os evangélicos. Este grupo tem expandido sua base de fiéis, sobretudo, entre as populações católicas das áreas urbanas de grandes cidades.

No Rio de Janeiro e em Rondônia, pentecostais representam grande maioria dos evangélicos. No Espírito Santo, cerca de 10\% da população é de evangélicos de missão, a maior participação relativa do Brasil. Na região Sul os pentecostais têm uma participação menor nos estados de Santa Catarina e Rio Grande do Sul, com uma participação mais relevante no Paraná, onde são 12\% da população contra $4,2 \%$ dos evangélicos de missão. 


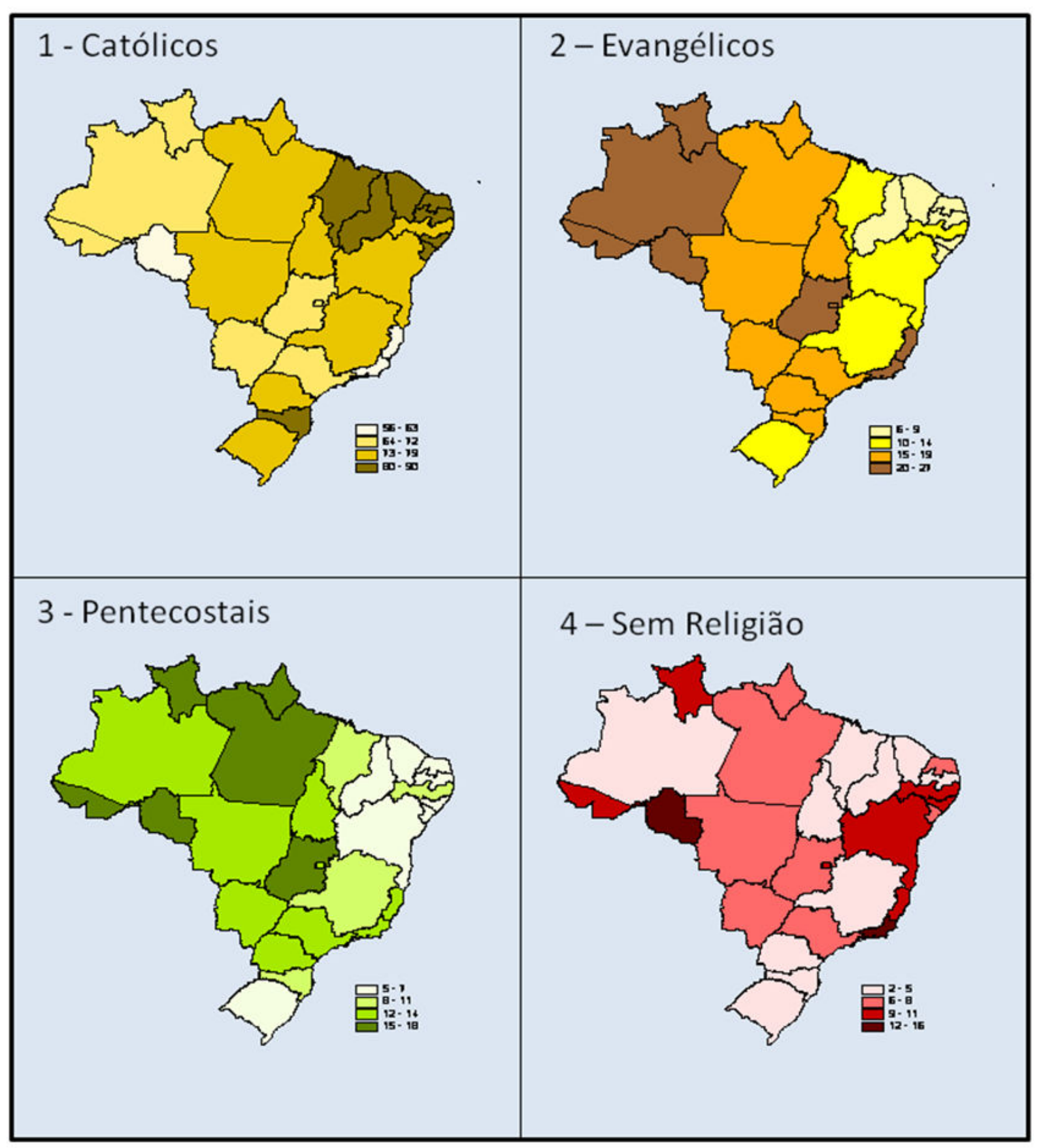

Fonte: Dados do IBGE.

Figura 3 - Mapas percentuais por grupo religioso 
O agrupamento sem religião congrega os ateus, agnósticos e aquelas pessoas que por algum motivo não se identificam com nenhuma religião. Este grupo é mais significativo no Rio de Janeiro, com 15,8\% da população, seguido por Rondônia, onde são 12,7\%. O menor percentual deste grupo ocorreu em Santa Catarina, onde apenas 2\% declararam-se Sem Religião. A média nacional deste grupo é 7,4\%. Na região sul este percentual é menor que a média nacional, o que também ocorre em alguns estados do Nordeste. No Centro-Oeste, Norte e Sudeste seus percentuais são superiores a média nacional.

Os estados de São Paulo, Rio de Janeiro e Rio Grande do Sul concentram cerca de $80 \%$ dos fiéis das religiões afro-brasileiras, com destaque para o Estado do Rio de Janeiro, onde são 1,3\% da população, e Rio Grande do Sul $(1,2 \%)$ contra $0,3 \%$ da média nacional. Na região Nordeste é pequeno o percentual das pessoas que se declararam como pertencentes às religiões afro-brasileiras. Deve-se considerar, entretanto, a importância do sincretismo religioso, onde as práticas afro-brasileiras encontram-se profundamente enraizadas no catolicismo popular.

Vendo a questão sob este aspecto, é importante destacar que os percentuais mais significativos observados nestes dois estados podem estar relacionados a uma identidade melhor definida dos crentes destes grupos no sul e sudeste que no nordeste. Outra hipótese pode ser o preconceito dirigido a estas religiões, com um agressivo proselitismo religioso por parte de algumas igrejas cristãs direcionadas a estes grupos.

As religiões espiritualistas apresentam os maiores percentuais relativos no Distrito Federal, cerca de 3\% da população. Em São Paulo, Rio de Janeiro, Goiás e Rio Grande do Sul os espiritualistas também representam uma parcela maior da população. Estes cinco estados concentram $65 \%$ dos espíritas do país, juntamente com Bahia, Minas Gerais e Pernambuco. Somados, estes oito estados representam $85 \%$ do total.

No caso das religiões espiritualistas, do mesmo modo que nas afro-brasileiras, é importante notar que parte da população que participa dos agrupamentos espiritualistas ou crê na totalidade ou em parte de suas doutrinas, continua se declarando como pertencente à outra religião. O perfil diferenciado dos adeptos destas religiões, já que em geral possuem a mais elevada renda per capita média, excluídas as religiões orientais. O perfil marcadamente urbano e a concentração espacial em estados mais industrializados ajuda a explicar esta característica.

Nas religiões orientais há uma concentração espacial no Sudeste e Sul, principalmente em São Paulo e no Paraná, que agregam os maiores contingentes de descendentes de orientais. O perfil desta população é destacado pela renda per capita mais elevada que a média nacional, o que pode ser explicado tanto pela região onde se concentram, como pelos maiores graus de escolaridade observados entre seus adeptos.

\section{Considerações Finais}

A análise dos dados do censo não se esgota nas informações apresentadas acima, pois são várias as características por explorar a partir dos micro-dados do censo. Uma possibilidade oferecida, que até hoje não foi explorada, é a avaliação do perfil populacional de cada denominação religiosa ou grupo, permitindo-se a comparação por estados e municípios. A desagregação dos dados municipais é outra possibilidade pouco explorada pelos estudiosos da questão no Brasil.

Todavia, a partir dos dados avaliados, é possível ter uma visão menos turva do aspecto demográfico do fenômeno religioso. As diferentes dinâmicas de colonização afetaram de forma diferenciada a distribuição dos agrupamentos religiosos pelo país. As migrações internas, sobretudo os movimentos campo/cidade, que se intensificaram a partir dos anos 1960/70, parecem guardar uma relação estreita com a mudança religiosa no país (MENDONÇA, 1984). Deste modo, é possível observar algumas mudanças mais significativas: o percentual de evangélicos e de pessoas sem religião é maior nas grandes cidades que nas áreas do interior do sul e do nordeste do país. Nestas regiões, que em geral foram "doadoras" de população nas décadas citadas, os percentuais de católicos é significativamente superior a média nacional.

Também é possível observar que o centro-oeste brasileiro, sobretudo os estados de colonização mais recente, como Rondônia, são áreas onde os agrupamentos evangélicos e os que se declaram sem 
religião são mais expressivos no país. Os agrupamentos que aparecem como espiritualistas e religiões orientais aparecem fortemente associados às variáveis alta renda e situação de domicílio urbana, com prevalência destes agrupamentos na região sudeste do país e nas grandes cidades. Isto reforça a característica de que as grandes cidades apresentam maior diversidade religiosa que as cidades pequenas e áreas do interior.

O processo de mudança religiosa, portanto, parece fortemente interligado com processos de migração populacional, o que eventualmente pode ser associado a questões como mudança de identidade ou perda do sentimento de pertencimento a grupos sociais específicos (COSTA, 1979). Este impacto da migração também pode ser visto quanto a outras instituições sociais, como a família, por exemplo, que passa a conviver com novos rearranjos a partir das transformações decorrentes da urbanização, como a inserção das mulheres no mercado de trabalho e o aumento da escolarização. Certamente, são questões que caminham juntas, cujo esclarecimento demanda maiores aprofundamentos sobre a relação entre a variável religião e os outros fenômenos decorrentes da urbanização.

Caso as tendências populacionais apontem para uma redução da importância das migrações no território brasileiro, propiciadas pelo virtual fim da fronteira agrícola e a maior estabilidade nas taxas de crescimento populacional, é possível imaginar como cenário futuro a redução do ritmo do trânsito religioso, com uma estabilização dos grupos evangélicos pentecostais, e mudanças nos percentuais religiosos ditadas mais pelo comportamento da taxa de crescimento vegetativo destes grupos do que pela mudança religiosa. Quanto aos novos agrupamentos religiosos surgidos, sua tendência também deve ser para a estabilização. As áreas de maior mudança no perfil religioso certamente continuarão a ser as cidades com crescimento acelerado e as áreas ainda restantes de fronteira agrícola. Estas hipóteses, contudo, só poderão ser averiguadas com as informações do censo 2010.

\section{Notas}

\footnotetext{
${ }^{1}$ Os Batistas, por exemplo, são conhecidos como Convenção Batista Brasileira; o que o IBGE chama de Igreja Congregacional Cristã no Brasil, se autodenomina de Congregação Cristã no Brasil; a Igreja Evangélica Adventista do Sétimo Dia, se auto-denomina apenas Igreja Adventista do Sétimo Dia, sendo o qualificativo Evangélico atribuído apenas pelo IBGE. Vários são os exemplos de confusão em relação a terminologia.
}

\section{Referência Bibliográfica}

ALMEIDA, R. Religião na metrópole paulista. Revista Brasileira de Ciências Sociais. Out. Vol. 19, n. ${ }^{\circ}$ 56. São Paulo, 2004. pp. 15-27.

ALMEIDA, A. A cabeça do brasileiro. São Paulo: Ed. Record, 2007

ANTONIAZZI, A. Por que o panorama da religião no Brasil mudou tanto? CONIC, Conselho Nacional das Igrejas Cristãs. 04/03/2007. Acesso em 5/6/2008. In: http://www.conic.org.br/ index.php?system=news\&news_id=375\&action=read

COSTA, E. B. Protestantism, modernization and cultural change in Brazil. Berkeley, University of California. Tese de doutorado, 1979. Não publicado.

ORO, A.P. Considerações sobre a liberdade religiosa no Brasil. Ciências e Letras. Porto Alegre. n.37, jan./jun. 2005. pp. 433-447. Acesso em 10/06/2008 In: http://www4.fapa.com.br/cienciaseletras/pdf/revista37/ cap20.pdf

MENDONÇA, A. G. O celeste porvir - A inserção do protestantismo no Brasil. São Paulo: Paulinas, 1984. NERI, M. A ética católica e o espírito da revolução feminina. Acesso em : 10/06/2008. http://www.fgv.br/ cps/religioes/Apresenta\%E7\%E3o/valor.pdf. 